\title{
O arrependimento após a esterilização cirúrgica e o uso das tecnologias reprodutivas
}

\author{
Repentance after surgical sterilization and the use \\ of reproductive technologies
} Rua Bernardino de Campos, 50, apto. 1101 - Centro CEP 14015-130 - Ribeir̃̃o Preto/SP E-mail: bmeloni@fmrp.usp.br
As informações mais recentes que temos sobre o uso de métodos anticoncepcionais para o território nacional são os dados da Pesquisa Nacional sobre Demografia e Saúde ${ }^{1}$ conduzida em 1996, que apontavam para alta prevalência de esterilização feminina $(40,1 \%)$ entre as mulheres de 15 a 49 anos em união sexual (casada ou em coabitação). O segundo método mais usado, em proporção bastante inferior, 21,4\%, era o anticoncepcional hormonal oral. Em estudo comparativo entre o Estado de São Paulo e o Brasil, de 1986 e $1996^{2}$, observam-se algumas tendências: até os 30 anos de idade, o anticoncepcional hormonal oral é prevalente e, a partir dessa idade, a esterilização feminina cresce. A esterilização feminina aumenta com o número de filhos e diminui com a escolaridade. A vasectomia era, naquela época, cinco vezes menos utilizada que a laqueadura, embora já se percebesse uma tendência de aumento de uso de métodos masculinos.

As altas taxas de esterilização feminina no país chamaram a atenção, na década de 80 e 90, de estudiosos de várias áreas: demografia, saúde pública, ginecologia/obstetrícia e sociologia. Até mesmo uma Comissão Parlamentar de Inquérito (CPI) ${ }^{3}$ foi criada para entender como ocorria essa desenfreada oferta. Vários estudos conduzidos no país ${ }^{4-9}$ tentaram entender como e por que a esterilização feminina fazia (e ainda faz) tanto sucesso, apesar de ser, na época, um procedimento que não estava legalmente regulamentado. Por isso, os Conselhos de Medicina afirmavam não ser ético realizar a esterilização, visto que o médico poderia sofrer as conseqüências previstas no parágrafo $3^{\circ}$ do Artigo 129 do Código Penal, que trata de lesões corporais, perda de órgãos ou funções ${ }^{10}$. Apesar das dúvidas sobre a sua legalidade, a oferta da esterilização, tanto feminina quanto masculina, tornou-se uma prática no setor privado ${ }^{11}$. As mulheres obtinham a esterilização clandestinamente pelo pagamento "por fora", na hora do parto, freqüentemente por meio de uma cirurgia cesariana ${ }^{12}$. Em Ribeirão Preto, cerca de $60 \%$ das mulheres esterilizadas durante uma cesariana, em 1998, pagaram pelo procedimento ${ }^{13}$. Outros estudos tentaram entender como a esterilização feminina foi usada como moeda de troca no país, favores políticos e votos ${ }^{14}$. Desnecessário dizer que durante esse processo ocorre acentuada queda na taxa de fecundidade no país.

A insuficiência do Estado em implantar e fornecer um planejamento reprodutivo adequado, que já havia sido desenhado no Programa de Atenção Integral à Saúde da Mulher (Paism) em 1984, entrou em primeiro lugar na lista de explicações para a altíssima prevalência de esterilização feminina. Também se chamou atenção para o caráter de

Professora Associada do Departamento de Medicina Social da Faculdade de Medicina de Ribeirão Preto da Universidade de São Paulo - USP - Ribeirão Preto (SP), Brasil. 
dissociação entre sexo e reprodução no uso da esterilização ${ }^{5}$, com a ação legitimadora do médico que confirma para a mulher que seu desejo de contracepção é válido, sério e deve ser considerado ${ }^{15}$, explicando, então, a preferência cultural da esterilização. Discutiu-se muito seu uso em uma situação quase obrigatória após duas cesáreas (outra preferência nacional $)^{16}$. Berquó (1993) alertou para uma cultura da esterilização ${ }^{16}$. Nesse contexto, destaca-se o papel da medicalização, que tomou lugar no vácuo de uma política pública que não foi implementada ${ }^{17}$.

Podemos olhar melhor para a alta prevalência da esterilização feminina no contexto maior da oferta de métodos contraceptivos pelo serviço público. O relatório técnico de uma missão do Fundo de População das Nações Unidas $(\mathrm{UNFPA})^{18}$ ao Brasil, em 1994, revelou vários problemas relativos ao planejamento familiar no país: a imensa lacuna entre a demanda por contraceptivos e o acesso a eles, a falta de insumos nos serviços públicos de saúde, a ausência de gerenciamento logístico, a falta de capacidade técnica das equipes. Uma análise detalhada sobre as características dos serviços prestados na área de saúde reprodutiva apontava para várias deficiências: predominância de apenas dois métodos anticoncepcionais, leque de escolhas reduzido, os métodos oferecidos demonstram medicalização excessiva, predominância do setor privado (compra de pílulas e ofertas de cirurgias), acesso tardio (quase $50 \%$ das mulheres começavam a fazer contracepção depois do primeiro filho), uso inadequado de contraceptivos, alta proporção de gravidez indesejada, falta de informação e desigualdade no acesso ${ }^{17}$.

Acrescenta-se a isso uma questão de gênero importante, pois são as mulheres que mais contribuem com a contracepção, já que a participação masculina, embora crescente, ainda não atinge os níveis de outros países, onde parece haver maior equilíbrio de gênero, principalmente no que se refere à esterilização.

A oferta de métodos contraceptivos em programas de saúde baseia-se nos direitos reprodutivos. A noção de direito reprodutivo como direito humano desenvolveu-se ao longo do século XX, sendo um fenômeno recente, relacionado às mudanças no papel das mulheres e seu valor na sociedade, às mudanças de consciência das mulheres sobre seu papel e valor e ao desenvolvimento das tecnologias médicas. Embora a Declaração Universal dos Direitos Humanos não mencionasse os Direitos Reprodutivos, a partir de 1968 a reprodução humana tornou-se objeto de preocupação. Os direitos reprodutivos foram definitivamente incorporados na Conferência Internacional sobre População e Desenvolvimento do Cairo, em 1994:

"Os direitos reprodutivos baseiam-se no reconbecimento do direito básico de todos os casais e indivíduos decidirem livre
e responsavelmente sobre o número, espaçamento e quando devem ter os filhos e de terem acesso a informação sobre a
forma como fazê-lo, bem como o direito de se beneficiarem de saúde sexual e reprodutiva do mais alto nível. Também
incluem o direito de todos tomarem decisôes sobre a reprodução sem discriminaçâ, coerção nem violência." (p.58) ${ }^{19}$.

Desde 1988, no Brasil, o planejamento familiar é um direito do cidadão, e é definido como um conjunto de ações de regulação da fertilidade, que objetiva garantir direitos iguais de constituição (limitação ou aumento de prole) pela mulher, pelo homem ou pelo casal. Deve ser parte integrante do atendimento à saúde, com ações preventivas e educativas no acesso igualitário às informações e meios de anticoncepção cientificamente aceitos. É dever do Estado assegurar o livre exercício do planejamento familiar. Mas foi somente a partir de 1997 que a oferta da esterilização cirúrgica voluntária passou a ser regulamentada no Brasil, com a aprovação da Lei 9.263, regulamentando o parágrafo $7^{\circ}$ do Artigo 226 da Constituição Federal. A lei 9.263 foi aprovada em janeiro de 1996, mas o Artigo $10^{\circ}$, sobre a esterilização cirúrgica, permaneceu vetado pelo Presidente até agosto de 1997. Composta de 25 Artigos e organizada em três Capítulos, a Lei aborda vários aspectos do planejamento familiar, estabelecendo que nenhum programa deva visar a metas demográficas. Fornece diretrizes claras para questões institucionais, alocando no Sistema Único de Saúde (SUS) as ações de planejamento familiar, como parte integrante da atenção à saúde reprodutiva, incluindo as atividades básicas de assistência à concepção e contracepção, o atendimento pré-natal, a assistência ao parto, ao puerpério e ao neonato, o controle das doenças sexualmente transmissíveis e o controle e prevenção do câncer cérvico-uterino, do câncer de mama e de pênis. Estabelece, ainda, que é dever do Estado assegurar o livre exercício do planejamento familiar e que a esterilização voluntária é somente permitida em duas situações:

- em homens e mulheres com capacidade civil plena e maiores de 25 anos ou, pelo menos, dois filhos vivos, desde que observado o prazo mínimo de 60 dias entre a manifestação da vontade e o ato cirúrgico, período pelo qual será propiciado à pessoa interessada acesso a serviço de regulação da fecundidade, incluindo aconselhamento por equipe multidisciplinar, visando desencorajar a esterilização precoce; 
- risco à vida ou à saúde da mulher ou do futuro concepto, testemunhado em relatório escrito e assinado por dois médicos.

Para desvincular a esterilização feminina das cesarianas, a lei veda a esterilização cirúrgica em mulher nos períodos de parto ou aborto, exceto nos casos de comprovada necessidade, por cesarianas anteriores. Prevê ainda fiscalização e controle pelo SUS das instituições que realizam planejamento familiar. Várias portarias e resoluções no nível federal e estadual, estabelecendo formas de controle, foram publicadas ${ }^{20,21}$. Em seu capítulo II, a Lei 9.263 prevê penalidades, definindo como crime as esterilizações em desacordo com a lei.

Embora a regulamentação legal dos direitos assegurados na Constituição Brasileira seja fundamental para garantir os direitos reprodutivos e melhorar a qualidade de vida das pessoas, apenas a regulamentação não seria suficiente para criar situações para o exercício dos direitos reprodutivos, como afirmam alguns autores ${ }^{22}$. Quando os mecanismos legais não são suficientes, então outros aspectos sociais, materiais e institucionais da sociedade precisam ser desenvolvidos para assegurá-los ${ }^{6}$. É o caso da oferta do planejamento familiar de boa qualidade que necessita de investimento na capacitação de profissionais, na compra de insumos e de bom desenvolvimento técnico e tecnológico para se efetivar.

Em sua ausência, há situações como testemunhamos neste estudo relevante realizado por pesquisadores da Universidade de Brasília apresentado nesta edição de $\mathrm{RBGO}^{23}$. Este nos informa sobre um contingente de 98 mulheres arrependidas que procuraram um serviço de reprodução assistida para conceber após terem sido esterilizadas.

O arrependimento após a esterilização é uma séria questão médica, porque, na maioria dos casos, a escolha da laqueadura é eletiva, não se pode garantir o retorno à fertilidade e existem alternativas contraceptivas mais reversíveis do que a esterilização que podem ser utilizadas com grande eficácia. $\mathrm{O}$ arrependimento já foi estimado entre 11 e $15 \%$ das mulheres brasileiras esterilizadas ${ }^{24}$.

Reconhecendo a dificuldade de medir com precisão o arrependimento, Marcil-Gratton ${ }^{25}$ usou um gradiente de sentimentos de arrependimento para classificar as mulheres em alguns grupos:

1. mulheres que nunca sentiram arrependimento;

2. mulheres que tentariam ter outro filho se não estivessem esterilizadas;

3. mulheres que conversaram com o médico sobre a reversão do procedimento;

4. mulheres que solicitaram a reversão da laqueadura para seus médicos.

Alguns fatores como idade jovem, falta de estabilidade no relacionamento conjugal e morte de filho são apontados em todo o mundo como predisponentes ao arrependimento ${ }^{23}$. No Brasil, além de ter motivos diferentes para satisfação com o número de filhos, destaca-se a idade jovem ao ter o primeiro filho como fator para o arrependimento, visto que predispõe à laqueadura jovem. Observou-se, também, que o pagamento atua como obstáculo ao arrependimento, de maneira que este pode aumentar após a oferta de esterilização gratuita pelo SUS ${ }^{6}$.

Dessa forma, é importante garantir que a escolha da esterilização seja feita de forma consciente e informada pelos indivíduos e que estes recebam aconselhamento e orientação sobre todos os métodos anticoncepcionais, inclusive os reversíveis, tal como prevê a Lei 9.263. Tem sido o caso do município de Ribeirão Preto, que, desde 1999, oferece a esterilização masculina e feminina pelo SUS com adequado suporte de aconselhamento realizado por profissionais de saúde capacitados. Mesmo neste caso não existem garantias de que não haja arrependimento entre os esterilizados, pois ele pode ocorrer mesmo após a escolha informada, como já foi explorado por vasta literatura em estudos realizados em diversos países ${ }^{23}$. A oferta conjunta da esterilização, tanto feminina quanto masculina, pelo sistema público representa uma novidade em termos de serviços de contracepção no Brasil, pois concentra, em um mesmo serviço, a oferta das duas cirurgias que anteriormente eram oferecidas por especialistas de duas áreas distintas e, aparentemente, sem conexões: ginecologistas e urologistas.

É importante notar, em concordância com alguns estudos ${ }^{6,23}$, que apenas uma pequena parcela de mulheres arrependidas estaria disposta a se submeter a essas técnicas para conceber e uma parcela menor ainda atinge seus objetivos. Em estudo realizado no Brasil, entre 79 mulheres arrependidas, apenas 19 (24\%) procuraram por informação sobre reversão ${ }^{26}$. No caso do estudo em questão, das 98 mulheres, apenas $8 \%$ tiveram o sucesso almejado. Das 20 mulheres submetidas à reversão da laqueadura, seis (30\%) tiveram o bebê a termo, e, entre oito mulheres submetidas às técnicas de fertilização in vitro com transferência de embrião, duas (25\%) obtiveram sucesso. Chama 
atenção que para 22 mulheres estava indicada fertilização in vitro com transferência de embrião, mas infere-se que elas fazem parte das que desistiram do procedimento.

O uso das tecnologias reprodutivas, cirurgia de recanalização tubária ou transferência de embriões não é inócuo, e pode causar dor e sofrimento. Existem riscos de gravidez tubária, abortamento, óbito neonatal e gravidez múltipla. O mais estarrecedor é que entre as 98 mulheres estudadas, 83,6\% afirmaram não terem tido informação suficiente a respeito do caráter definitivo da laqueadura tubária. Ou seja, uma decisão definitiva como a esterilização cirúrgica foi tomada sem a informação necessária. Essa distorção fere os direitos reprodutivos. A sociedade deve aperfeiçoar suas regulamentações e normas, de forma a garantir o bem-estar dos indivíduos e os limites de responsabilidade profissional. O currículo médico na área deve incluir discussões sobre bioética e direitos reprodutivos, para evitar situações como essas. É necessário também ao médico ter consciência do processo de medicalização, pois a sociedade pode colocar em suas mãos decisões e responsabilidades enormes.

Refletindo recentemente sobre um texto de Bateman ${ }^{27}$, que afirma que a atuação médica na manipulação das tecnologias reprodutivas difere de outros procedimentos médicos já atuantes sobre o campo da não-doença, separando definitivamente o sexo da reprodução e colocando para a medicina questões éticas, morais e políticas jamais pensadas pela humanidade, apontamos para a medicalização como processo de tomada do objeto do conhecimento do campo do não-médico para o médico. Para Conrad ${ }^{28}$, a medicalização contém, em si, uma questão conceitual, ou seja: o problema é definido em termos médicos, usa-se uma linguagem médica para descrevê-lo, adota-se um referencial teórico médico para entendê-lo ou usa-se a intervenção médica para tratá-lo. É um processo sociocultural que pode ou não envolver a profissão, conduz a um controle médico social ou tratamento médico, ou é resultado de uma expansão intencional da profissão médica. No caso de mulheres cirurgicamente esterilizadas e tratadas com tecnologias reprodutivas, pode-se colocar o problema desta medicalização, provavelmente, como a de expansão não intencional da prática médica, mas que coloca em jogo um dos princípios éticos essenciais a essa prática revelado pelo aforisma primum non nocere (primeiro, não ferir).

$\mathrm{Na}$ análise dessa situação, outras questões poderiam ser incluídas: em que condições se dão essas escolhas reprodutivas? Houve aconselhamento? Houve consciência dos sujeitos envolvidos nessa decisão? Deve aconselhar o procedimento de esterilização o indivíduo que receberá pagamento por ele? Devem ter acesso às tecnologias reprodutivas todos os indivíduos que se arrependeram de um procedimento tão definitivo quanto a esterilização cirúrgica?

Há necessidade de maior debate sobre a bioética e suas condições de desenvolvimento, promovendo a reflexão dos profissionais sobre sua prática que, provavelmente, se realizou fundada em boas intenções. É necessário que o entendimento e o desenvolvimento de tecnologias educacionais de aconselhamento, orientação, conversa e amplo acesso a métodos sejam esgotados antes de uma decisão definitiva como essa. Para tal, o profissional médico necessita de outros profissionais para compartilhar seu trabalho. A ausência de uma estrutura de múltiplos olhares profissionais que apóie os envolvidos nos processos de decisão os abandona à própria sorte em tomadas de decisões complexas e difíceis. A ausência de regulamentações sobre as tecnologias deixa médicos e requerentes à margem de um processo justo e igualitário, em termos de direitos e escolhas.

\section{Referências}

1. Sociedade Civil Bem-Estar Familiar no Brasil (Bemfam). Pesquisa nacional sobre demografia e saúde - PNDS 1996. Rio de Janeiro: Bemfam/Macro; 1997.

2. Vieira EM, Badiani R, Fabbro ALD, Rodrigues Junior AL. Características do uso de métodos anticoncepcionais no Estado de São Paulo. Rev Saúde Pública. 2001;36(3):263-70.

3. Barroso C. Esterilização no Brasil. Brasília: Comissão de Estudos de Direitos da Reprodução/MS; 1988.

4. Berquó E. A esterilização feminina hoje. Ciênc Tecnol. 1989;88(5):598-610.

5. Barroso C. Esterilização feminina: liberdade e opressão. Rev Saúde Pública. 1984; 18(2):170-80.

6. Vieira EM. Regret after female sterilization among low-income women in São Paulo, Brazil [thesis]. Exeter: University of Exeter; 1994.
7. Osis MD. Laqueadura e representações acerca da sexualidade e do papel reprodutivo [tese]. São Paulo: Universidade de São Paulo; 2001.

8. Serruya S. Mulheres esterilizadas: submissão e desejo. Belém: Naea/Afpa/Uepa; 1996.

9. Minella LS. A produção científica sobre esterilização feminina no Brasil nos anos 80 e início dos anos 90: um debate em aberto. Rev Bras Estud Popul. 1998;15(1):3-22.

10. Conselho Regional de Medicina do Estado de São Paulo (Cremesp). Aspectos éticos que envolvem a esterilização. Ética Méd. 1988;1(1):67.

11. Berquó E, Cavenaghi SM. Direitos reprodutivos de mulheres e homens face à nova legislação brasileira sobre esterilização voluntária. Cad Saúde Pública. 2003;19 Supl 2:441-53. 
12. Vieira $E M$, Ford NJ. The provision of female sterilization in São Paulo, Brazil: a study among low income women. Soc Sci Med. 1996;42(10): 1427-32.

13. Vieira EM, Ford NJ. Provision of female sterilization in Ribeirão Preto, São Paulo, Brazil. Cad Saúde Pública. 2004;20(5):1201-10.

14. Caetano AJ. Sterilization for votes in the Brazilian Northeast: the case of Pernambuco [thesis]. Austin: University of Texas; 2000.

15. Vieira EM. A medicalização do corpo feminino. Rio de Janeiro: Fiocruz; 2002

16. Berquó E. Brasil, um caso exemplar: anticoncepção e partos cirúrgicos à espera de uma ação exemplar. Estud Fem. 1993; 1 (2):366-81.

17. Vieira EM. Políticas públicas e contracepção no Brasil. In: Berquó E, organizador. Sexo e vida: panorama de saúde reprodutiva no Brasil. Campinas: Unicamp; 2003. p. 151-96.

18. United Nations Population. Contraceptive requirements and logistics management needs in Brazil. New York: FNUAP; 1995. (Technical Report, 21).

19. Nações Unidas. Relatório da Conferência Internacional sobre População e Desenvolvimento; 5 -13 set 1994; Cairo. Brasília: Comissão Nacional de População e Desenvolvimento/ FNUAP; 1994.

20. Ministério da Saúde. Secretaria de Assistência à Saúde. Portaria n. ${ }^{\circ} 144$ de novembro de 1997. Dispõe sobre..... Diário Oficial da União, Brasília (DF) 20 nov. 1997;(227).
21. Resolução SS-5, de 11 de janeiro de 2000. Dispõe sobre Estabelece critérios para a efetivação dos procedimentos de esterilização no âmbito do Estado de São Paulo. Diário Oficial do Estado de São Paulo, Poder Executivo, São Paulo jan. 2000; Seç.l (110): p. 13.

22. Freedman LP, Isaacs SL. Human rights and reproductive choice. Stud Fam Plann. 1993;24(1):18-30.

23. Cunha ACR, Wanderley MS, Garrafa V. Fatores associados ao futuro reprodutivo de mulheres desejosas de gestação após ligadura tubária. Rev Bras Ginecol Obstet. 29(5):230-4.

24. Vieira EM. O arrependimento após a esterilização feminina: é possível prevenir? Reprod Clim. 1999;14(4):178-84.

25. Marcil-Gratton N. Sterilization regret among women in metropolitan Montreal. Fam Plann Perspect. 1988;20(5):222-7.

26. 26. Vieira EM. Arrependimento após a esterilização feminina. Cad Saúde Pública. 1998;14 Supl 1:59-68.

27. Bateman S. When reproductive freedom encounters medical responsibility: changing conceptions of reproductive choice. In: Vayena E, Rowe PJ, Griffin PD, editors. Current practices and controversies in assisted reproduction. Report of a WHO meeting. Geneva: World Health Organization; 2002. p. 320-32.

28. Conrad P. Medicalization and social control. Annu Rev Sociol. 1992; 18:209-32. 